\title{
Working the Crowd: Behavior Management through Strategic Classroom Arrangement
}

\author{
Jeff Martin
}

Every day in K-12 classrooms across the country, teachers are struggling to keep their students focused and on task during

instructional time. There are hundreds of theories floating around about how to manage a classroom effectively, but nothing

is as simple or as effective in engaging students as the physical presence of the teacher (Brophy, 1988). It does not matter if

the teacher is six feet or four feet tall, male or female, a soft spoken person, or a forceful one because if done correctly, rarely

will a word ever need to be spoken for this strategy to work. This is a strategy made famous by Fred Jones (2007), a nation-

ally known classroom management guru, and is called "working the crowd." There is a popular saying about the value of

an ounce of prevention. Taking the time to set up a classroom properly before students ever arrive will result in in a smoothly

managed classroom from the first day.

\section{PROXIMITY AND MOBILITY}

In its simplest form, working the crowd refers to proximity in the classroom. It is all about where the teacher is standing in relation to the seats of the students. Here is a basic example. Where does all the goofing off in a classroom typical happen? Of course, it happens in the back of the room or any point that is as far from the teacher as possible. The greater the distance between the teacher and student, the more likely there will be unacceptable behavior happening. Teachers must always be aware of where they are standing in relation to their students, and how long it will take for the teacher to reach the misbehaving student. These few seconds can make a massive impact with the tone of the classroom.

It is all about crowd control. This is a term most often thought of in large groups at a football game or music concert. Many would argue that any classroom in American can be viewed as a crowd. Unfortunately, student counts ranging from 25 to 35 plus are becoming very common in American schools (Wong, 2004). These numbers are definitely considered a crowd. Now, if teachers change their thinking to the idea that they are working with a group versus individual students, the management concept of crowd control will make perfect sense. Is it possible to have every student on task $100 \%$ of the time? Of course not, but the goal should be to have most of the students doing most of their work most of the time. Working the crowd is a basic skill. As Jones (2007) says, either we work the crowd, or the crowd will work us. Taking the time to map out a plan will give teachers the best opportunity to successfully manage these crowds they have been asked to handle for 180 days each year.

\section{ZONES OF PROXIMITY}

The first step in creating this plan is to understand the zones that exist in classrooms. There is a red zone, yellow zone, and green zone that surround a teacher. Think about these ideas compared to traffic lights: Stop, slow down, or hit the gas when nobody is looking. Different behavior is occurring within each of these zones all day long. The kids are constantly thinking to themselves, “... is the coast clear?" The teacher stands up in front of the classroom and his or her body is turned to write something on the board. What is happening in the classroom behind the teacher's back? The green 
light has just been given to those kids who want to misbehave in class. By learning how these different color zones work and the impact the teacher's physical proximity has in relation to student behavior, situations like this can be avoided much easier.

\section{RED ZONE}

The red zone is the area approximately 8 feet around the teacher. As he or she moves throughout the classroom, so does the red zone. What kind of behavior can be expected from the students who are in the red zone? Generally speaking, students will be on task, working on assignments, or listening intently to the teacher's every word. Teaching life would be perfect if every student were in the red zone all day. An effective teacher should always strive to get as many kids in the red zone as often as he or she can. This can be accomplished by simply moving throughout the room regularly. Obviously, this can never happen if the teacher is sitting behind his or her desk. The teacher needs to be out mixing among the students. If a negative behavior occurs that needs to stop, the teacher can walk over and simply stand there next to the student. Rarely will a word need to be spoken. The physical presence is often enough to stop this behavior. The student is in the teacher's red zone, and he or she has complete control without doing anything other than moving throughout the room. Unfortunately, it is not possible to have all students in the red zone at all times, but there are simple tricks to increase the frequency.

\section{YELLOW ZONE}

The yellow zone runs between 8 feet and 15 feet from the teacher (Jones, 2007). Think of this as the caution zone. For many classrooms, this may not be much less than the width of the classroom. Generally, students can be expected to behave the same way as if they were in the red zone. This is true unless the teacher turns his or her back or walks away. At this point, the less trustworthy students will test the waters a little and begin to act up. If teachers are continually moving, most students will not even notice the fact the teacher is not standing right next to them. Constantly moving throughout the classroom will place more students in the yellow and red zones, and the atmosphere will be much more calm and manageable.

\section{GREEN ZONE}

Now, the green zone covers any student who is more than 15 feet away from the teacher (Jones, 2007). Just like the traffic light, green means GO for those students who are looking for an opening and opportunity to goof off. These kids typically do not act up right away once they realize they are in the green zone. They will cautiously wait their time to make sure the teacher is not coming back their way. They know how long it will take for the teacher to get back over to them to stop their behavior, and they will take full advantage of this opportunity. They do not necessarily have to be the extremely challenging kids. Any model student, given opportunity to do so, will fall off task if left on their own long enough.

Figure 1 is an example of the traditional classroom set up that most teachers grew up with in public school. The teacher's desk is at the front near the board and the desks are in straight rows with aisles from wall to wall. So, where do the challenging kids like to sit? Of course, they like to sit in the back of the room. The fact that the teacher is in the front of the room at the board automatically places these kids in the back inside the green zone. It will take more than 15 steps to get back to these kids, and by the time this happens, the negative behavior is often completed, and the teacher has just wasted more time in class.

\section{THREE RULES OF MOVEMENT}

There are three basic rules of movement to make working the crowd effective in a classroom. Practicing these will help them become second nature to any teacher.

1. Constantly change zones. Nobody should stay in the green zone too long. Remember, it only takes two or three steps to change the zone for any student.

2. Stimulate their brains by constantly changing their fields of view. There are times the teacher must lecture and deliver content, but how this is done makes all the difference. Do not become a talking head. Movement will keep students engaged and learning.

3. Use movement as camouflage for dealing with disruptive students. Verbally calling out a challenging student can quickly backfire. If a student becomes embarrassed 
because he or she was singled out, they often becomes defensive and the behavior can worsen. By moving and disrupting the comfort of these students, teachers will stop much of this negative behavior before it has the chance to begin.

\section{STRATEGIC ROOM ARRANGEMENT}

The room arrangement is the biggest obstacle for teachers moving throughout the classroom. Teachers are limited by the square footage of the room, but they do have control of the desk arrangements used. At the same time, the classroom arrangement can be one of the most effective tools a teacher can use to give themselves the upper hand in managing the classroom environment. Teachers should give themselves the best opportunity to succeed and make their lives as easy as possible. This all begins with creating an effective classroom arrangement.

\section{ARRANGING THE ROOM FOR TEACHING}

By far, the most common classroom arrangement is the straight row setting (Figure 1). Who created this arrangement? It is highly doubtful an effective teacher had any hand in this decision. Most likely it was the janitor who did this to make his or her life easier when cleaning each evening (Jones, 2007). While all teachers should respect and appreciate the job these people do to help keep schools running efficiently, they are not the people charged with teaching the children. Teachers need to arrange their rooms to make teaching and moving throughout the room as convenient and effective as possible. It does not matter the subject or age group taught; every teacher can make their classroom arrangement more effective.

The teacher's desk is the first obstacle to mobility in the classroom. Picture a classroom from 30 or 40 years ago. The desk was typically front and center or in front and slightly off to the side. Why does it need to be up front? The best place to park this desk is in the back corner of the room. One should not be sitting behind it; the desk acts as a barrier for the teacher to navigate. If teachers are sitting behind their desks, it will take five or six steps alone just to get out from behind it. This would put $75 \%$ of the classroom in either the yellow or green zones (Jones, 2007).
There are several questions teachers need to ask when determining the best room arrangement for working the crowd.

1. Where are the windows?

2. Where will I stand when I deliver my lectures or content for class?

3. Where are the doors?

4. Where is the dry-erase or smart board?

5. Where can I create and interior loop or runway?

Sitting down and drawing out these items on paper will help the visualization process and give the teacher the best opportunity to create the optimal arrangement.

\section{THE INTERIOR LOOP}

The interior loop is a simple way of creating a path for the teacher to walk (Figure 2). If the goal is to continually change zones, the teacher needs to arrange the desks to allow themselves the opportunity to place as many students in the red zone with the fewest steps possible. These interior loops do just that. As the teacher walks the loop, students' eyes will follow, keeping their attention much longer than if the teacher was standing in a single location. An arrangement with interior loops will allow the teacher to place challenging students in the most ideal location to keep them in the red zone as long as possible. By walking laps and wearing a path in the carpet around this interior loop, no single student will be allowed to be in the green zone for very long.

The interior loop can easily be created for cooperative learning teams (Figure 3). The same concept applies. Create a loop to give the teacher the chance to cover as much ground as possible with as little effort as possible. Figure 4 shows a unique layout using the path concept versus a loop. The same ideas apply here. With this layout, the teacher may spend the majority of his or her time in the center stage of the room and working each of the small clusters of students. Figure 5 is another arrangement that works very well. The teacher's stage would be in the middle, and most students can be in the red or yellow zone without a step even being taken. This layout also provides a path between the two U-shapes for the teacher to walk and monitor during both lecture and individual work time. The most challenging students will always be placed in the interior U-shape. Figure 6 provides 
a mixture of the traditional row system, if that is what the teacher is most comfortable with, but also provides both a path and loop to cover.

\section{CONCLUSION}

Teaching in the K-12 environment is becoming more challenging each year. Engaging students through simple classroom arrangement and teacher proximity is a strategy anyone can incorporate to quickly improve the learning atmosphere. Through structuring the arrangement of the desks, a teacher is able to move more freely throughout the classroom and engage the students; in using the three rules of movement, combined with the concept of the zones of proximity, teachers can greatly increase their ability to keep students on task without increasing their efforts or levels of stress. Students inherently want to follow the rules and behave appropriately, and through working the crowd and strategic classroom arrangements, teachers provide their students an opportunity to do just that.

\section{References}

BBrophy, J. (1988). Educating teachers about managing classrooms and students. Teaching and Teacher Education, 4, 1-18.

Jones, F. (2007). Tools for teaching: Discipline, instruction, motivation. Santa Cruz, CA: Fredric H. Jones \& Associates.

Wong, H.K. (2004). Induction programs that keep new teachers teaching and improving. NASSP Bulletin, 88(638), 41-58

Figure 1. Traditional classroom set up with rows and aisles.

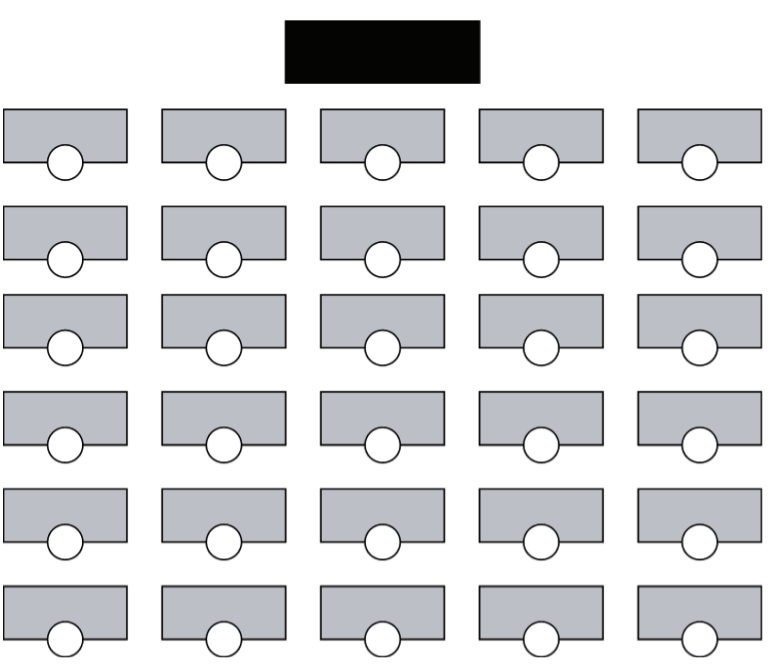

Figure 2. Basic interior loop classroom desk arrangement.

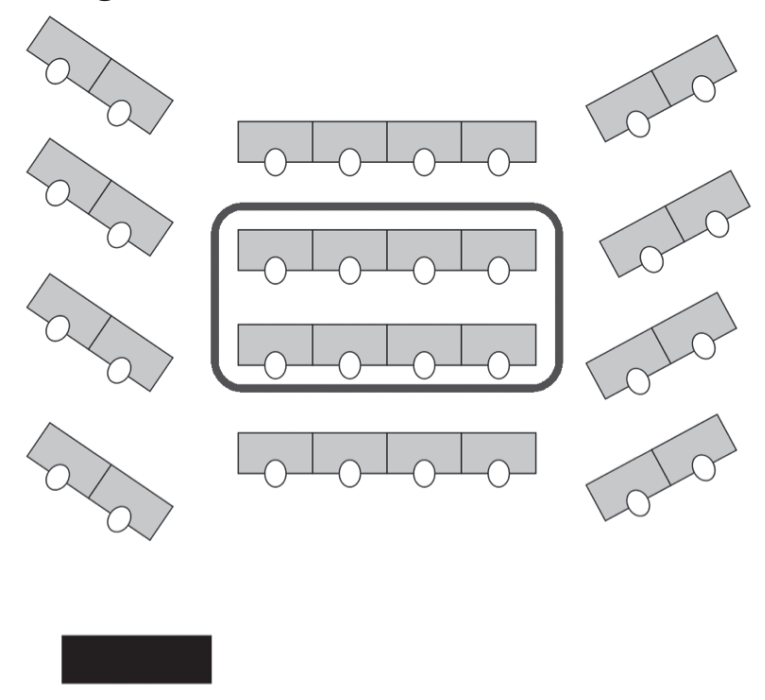

Figure 3. Interior loop in teams desk setting.
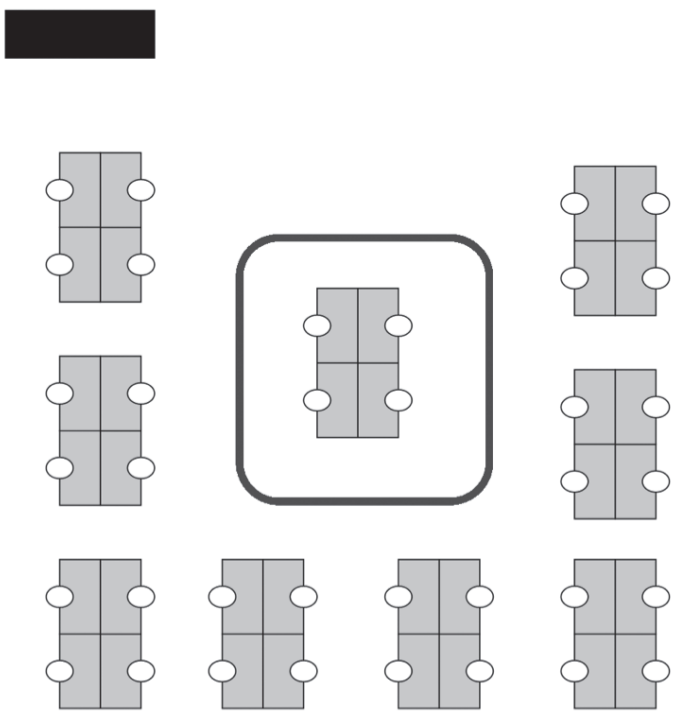
Figure 4. Alternative set up with center stage and pathway.

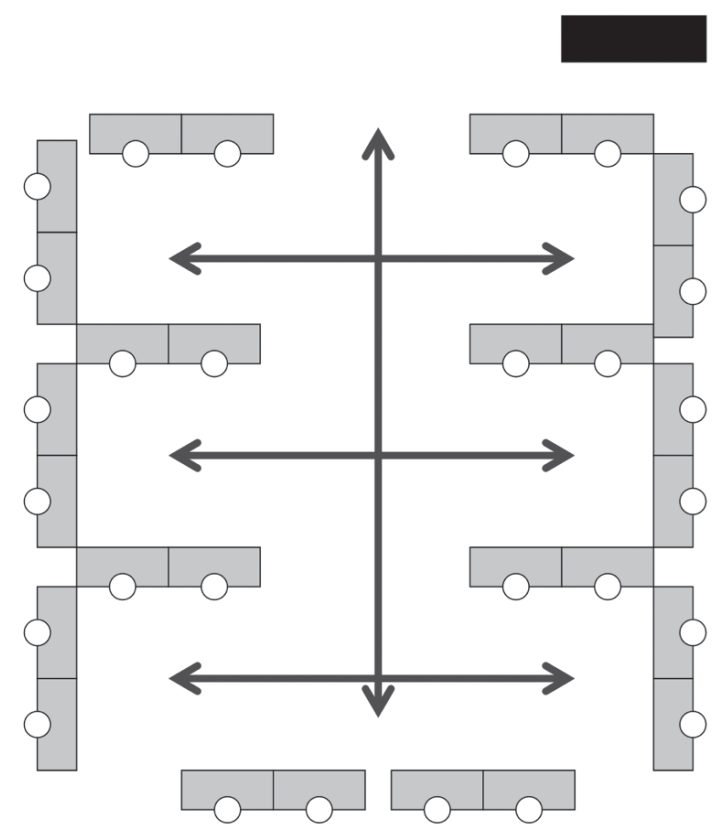

Figure 5. Alternative set up with center stage and pathway.

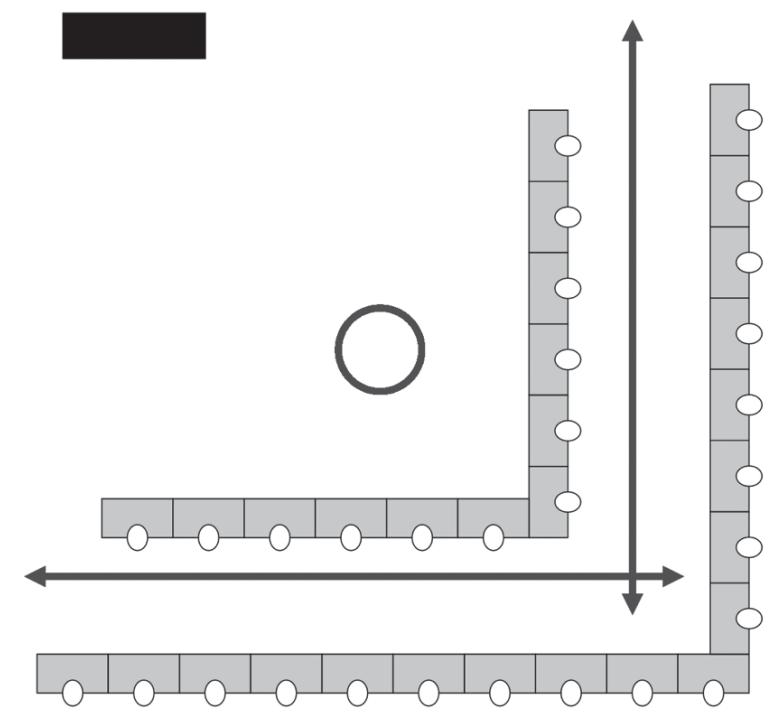

Figure 6. Interior loop with traditional row setting.

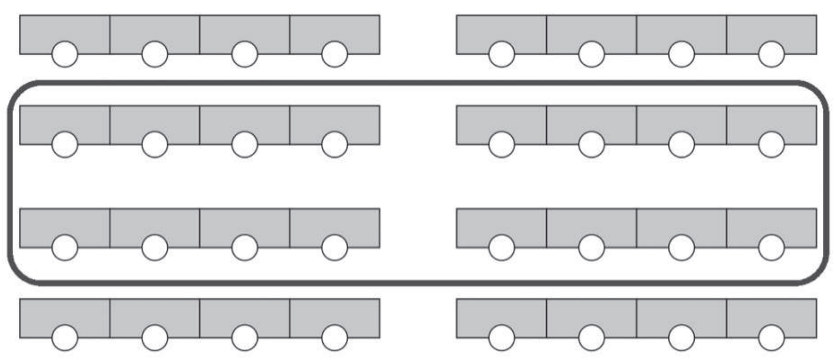

\section{Author Biography}

Jeff Martin is an instructor in the College of Education at Grand Canyon University. Prior to joining the staff at GCU, he taught high school and middle school English throughout the state of Arizona for eighteen years. Jeff is currently working on his EdD, and dissertation work is focused on classroom management and the perceptions of novice high school teacher regarding their pre-service training experience. Jeff has presented on the topic of classroom management at various Arizona statewide conferences, and he has a passion for helping teachers in with the critical strategies needed to effectively handle behavioral and management issues in the classroom. 